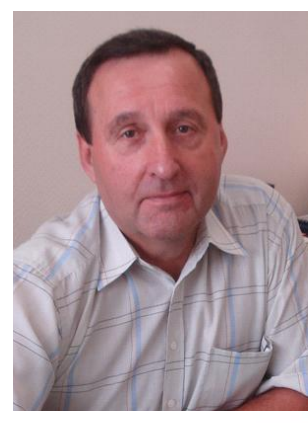

УДК [631.151.6:339.137.2]: 63.021

https://doi.org/10.47612/978-985-7149-55-1-2020-87-90

Михаил Запольский, доктор экономических наук, профессор, заведующий отделом организации аграрного бизнеса Институт системных исследований в АПК НАН Беларуси, г. Минск

\title{
Участие в международных интеграционных структурах как фрактор повышения конкурентоспособности продукции МHCTИTV отечественного АПК
}

Одним из основополагающих направлений функционирования мировой экономики выступает прогрессирующая глобализация в качестве нового этапа международной экономической интеграции. Наряду со многими привнесенными в мировую экономику качественными элементами она породила глобальную конкуренцию, заставшую национальные экономики на разных стадиях развития. Их выживаемость в условиях постепенного стирания межстрановых барьеров определяется конкурентоспособностью, которая в современный период превратилась в важнейшую составляющую экономического выживания национальных хозяйств.

Международная экономическая интеграция является одним из наиболее распространенных и одновременно одним из наиболее противоречивых феноменов современной мировой экономики. Развитие интеграционных объединений, являясь вместе с тем многоплановым и многофакторным процессом, требует учета существенных особенностей экономического развития и сотрудничества конкретных групп интегрирующихся стран.

Практика показывает, что на формирование интеграционной мотивации на межнациональном уровне в современных условиях начинают воздействовать новые вызовы экономического развития. В векторе развития белорусской экономики все в большей степени ощущаются последствия недостаточной конкурентности внутреннего рынка и качества экономического роста. В таких условиях интеграционные объединения вынуждены менять свои очертания и масштабы, что неизбежно вызывает потребность модификации экономического взаимодействия входящих в него стран.

В связи с этим анализ проблем и противоречий экономической интеграции стран (прежде всего Евразийского экономического союза) не только приобретает особую актуальность и практическую значимость для их успешного интегрирования, но и выступает необходимым условием для выработки экономической модели эффективного функционирования агропромышленного производства с целью повышения качества готового продовольствия, поставляемого на совместные рынки. В данном контексте первостепенное значение для отечественного АПК имеет присутствие нашей высококачественной продукции на рынке России в рамках функционирования Союзного государства, что обусловлено рядом факторов:
- белорусский промышленный и аграрный комплекс изначально ориентирован на российский рынок, при этом Беларусь обладает относительно емким рынком сбыта для товаров традиционного российского экспорта;

- Беларусь обладает значительным экономическим потенциалом, высоким уровнем квалификации рабочей силы, развитой транспортной инфраструктурой, что создает объективные предпосылки для вложения российского капитала с минимальными издержками и создания на этой основе необходимого задела для более активного вхождения в систему мирохозяйственных связей;

- в ходе реализации интеграционного сценария российско-белорусского взаимодействия достигнут высокий уровень торгово-экономического сотрудничества в различных сферах хозяйства, о чем свидетельствует статистика взаимной торговли и инвестиционных потоков между двумя странами;

- близость Беларуси к европейским рынкам и центрам экономической активности позволяет использовать ее в качестве экономического «моста» между Европой и азиатскими регионами России;

- развитие интеграционного взаимодействия России и Беларуси способствует поддержанию стабильности и безопасности российского транзита в Европу.

Выполненные исследования показывают, что создаваемые интегрированные структуры способствуют одновременному решению трех взаимосвязанных, но противоречивых групп задач по повышению конкурентоспособности аграрной продукции, поставляемой на внешние рынки:

- создание условий и механизмов концентрации и перераспределения имеющихся ресурсов национальных АПК, привлечение инвестиций и создание условий для накопления критической массы капитала (особенно в форме научного потенциала и человеческого капитала) для повышения качества конечной продукции за счет реализации инновационных проектов и программ;

- оптимизация региональных продуктовых рынков, создание инфраструктуры (прежде всего логистической), а также эффективных снабженческо-сбытовых и иных структур, обеспечивающих снижение издержек по доставке того или иного продукта до конечного потребителя;

- формирование необходимого количества институциональных структур, которые смогут в полном объеме согласовывать интересы участников объединений в части контроля качественных характеристик продовольствия 
(прежде всего скоропортящегося), соблюдения санитарных и экологических норм и требований.

Анализ практики превращения национальных компаний в мощные транснациональные компании (ТНК) показывает, что основным путем такого становления является наращивание экспортных операций за пределами страны первоначального базирования не только путем покупки (поглощения) профильных фирм и компаний, но и за счет использования передовых разработок по улучшению качественных и органолептических свойств готового продукта, что позволяет оптимизировать систему производственно-сбытовых цепочек материнской компании.

В данном контексте нами выявлены основные способы повышения конкурентоспособности выпускаемой продукции за счет интеграционной составляющей:

- частичная покупка профильного перспективного бизнеса соперников;

- создание совместного бизнеса (совместного предприятия) с зависимым партнером с целью расширения как объемов производства, так и ассортимента продукции, востребованной рынком в той или иной стране;

- слияние своего бизнеса с бизнесом интегрируемого конкурента, оказавшегося в сложном финансовом положении;

- приобретение недооцененной по брендинговому развитию компании, способной приносить в перспективе стабильные доходы без серьезных дополнительных инвестиций;

• поглощение утрачивающего позиции конкурента для укрепления конкурентных достижений в освоенном секторе/сегменте рынка путем развития перспективных экспортно ориентированных производств с использованием новейших технологий по глубокой переработке сырья и др. [7].

Нами обоснованы преимущества и значимость участия субъектов интеграции отечественного АПК в создании совместных интеграционных структур для повышения конкурентоспособности их продукции (по соотношению цена - качество), а именно:

- реализация масштаба используемых ресурсов (производственных, инвестиционный, трудовых), в том числе возможности привлечения квалифицированного производственно-управленческого и научного потенциала участников объединения;

- минимизация для участников отрицательного воздействия конкуренции бизнес-структур (особенно на внешних рынках), поскольку хозяйствующие субъекты выступают под одним брендом;

- производство конкурентоспособной продукции вследствие создания самодостаточной интегрированной системы выпуска законченной продукции глубокой степени переработки;

• значительная централизация инвестиционных возможностей, которые в зависимости от экономической и рыночной конъюнктуры могут «перетекать» от одного участника к другому;

- диверсификация межстранового производства для снижения предпринимательских рисков и оптимизации специализации отдельных видов деятельности странучастников как условия их конкурентоспособности;

- совместное использование передового технического опыта и прорывных научно-исследовательских разработок, которыми обладают участники интеграционной структуры;

- выработка и реализация совместной стратегии (производственной, финансовой, маркетинговой) производства высококачественного конкурентного продовольствия и его продвижения на мировые рынки;

- формирование условий для использования всеми участниками объединения рыночных методов управления своей деятельностью, переход от административного управления к менеджерскому и др.

Весь приведенный спектр сложившихся реальных условий функционирования конкурентоспособных связей в сфере агропромышленного бизнеса требует от отечественных аграриев адекватных организационноправовых действий по сохранению и укреплению достигнутых позиций по экспортно ориентированному развитию АПК на основе использования передовых научных разработок.

Практика показывает, что главной целью создания любой интеграционной структуры является получение синергического эффекта (эффекта от совместной деятельности), так как в противном случае нет смысла в ее создании. При этом эффект может быть стратегическим, экономическим, социальным и т. п., который нельзя получить в условиях деятельности разрозненных предприятий.

Очевидно, что совокупный эффект от интеграционного объединения значительно выше при создании крупных и крупнейших продуктовых компаний, так как появляется возможность привести производственную инфраструктуру (производство сырья и его переработка) в соответствие с инфраструктурой сбыта и торговли. В этом случае совместный менеджмент технологически зависимых предприятий позволяет добиваться высоких финансовых результатов за счет опережающего прогнозирования изменения конъюнктуры потребительского спроса.

В последние годы республика в целом достигла уровня продовольственной безопасности, чему способствовало сохранение крупнотоварного производства, обоснованная его концентрация и специализация, технологическая модернизация перерабатывающих предприятий и т. п. Поэтому вполне закономерно, что созданная база может и должна служить ступенькой для достижения более высокой цели - усиление продовольственной конкурентоспособности национального АПК в рамках международных интеграционных структур. Образно выражаясь, нам необходимо взрастить «дерево конкурентоспособности национального АПК», быстрый и качественный рост которого возможен на основе эффективного взаимодействия различных сфер деятельности (полей) с привлечением новейших технологий мирового уровня, отечественного и иностранного капитала (в первую очередь России и Казахстана), а также активного участия отечественных брендовых предприятий и компаний в деятельности транснациональных продовольственных компаний соответствующего профиля (рис.). 

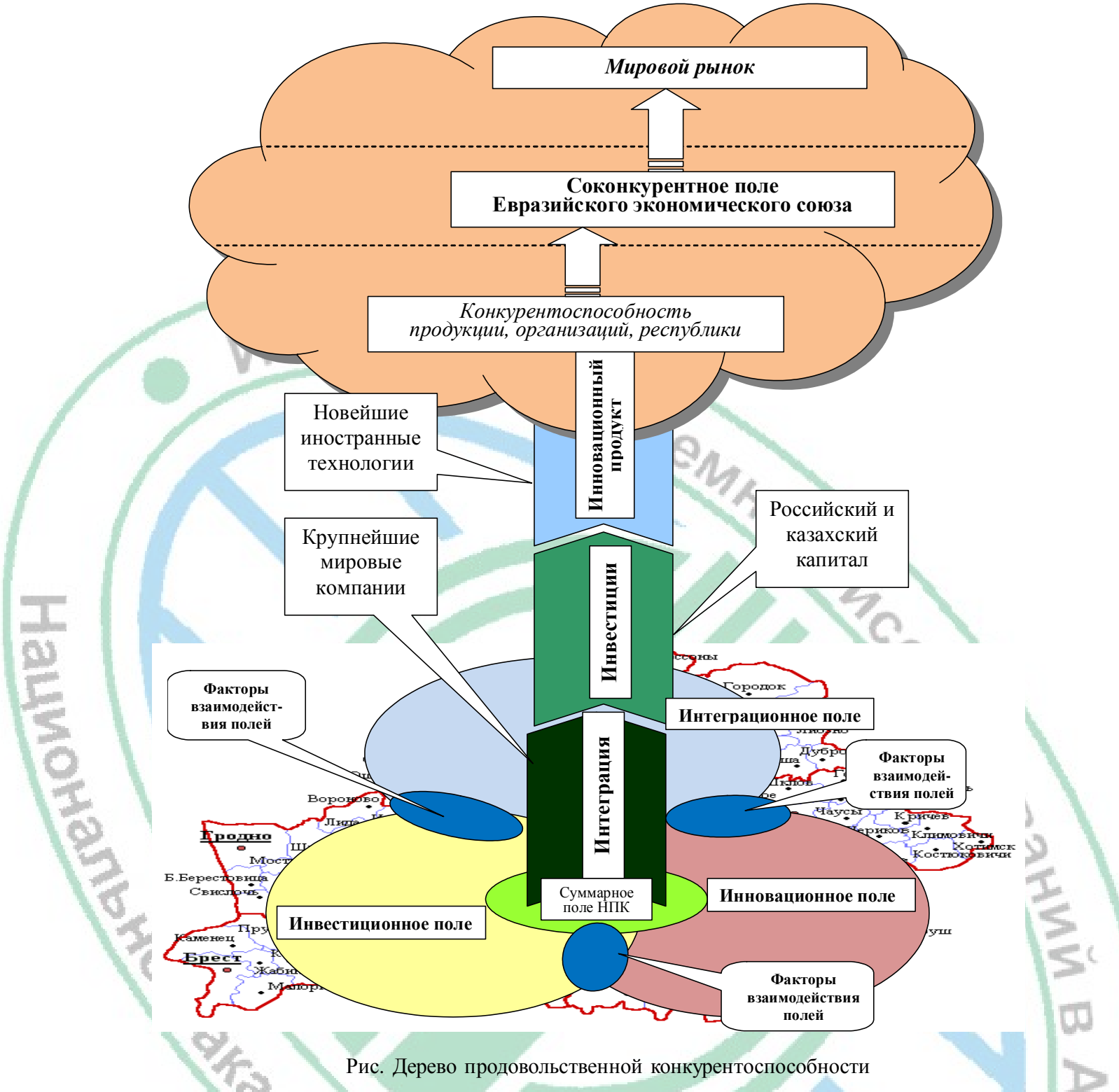

Таким образом, выполненные исследования позволяют сделать следующие выводы и обобщения:

1. Актуальность усиления продовольственной конкурентоспособности предприятий отечественного АПК на основе повышения качества конечной продукции определяется условиями глобализации и характеризуется уровнем синергетических эффектов от этого процесса, стандартизацией и гармонизацией правовых и экономических отношений, технических средств и коммуникаций; регулированием нормативов качества продовольствия, которое на протяжении последних лет стало важнейшей задачей государственного управления продовольственным рынком. Вместе с тем отечественные товары находят спрос в основном за счет их более низкой стоимости. В данной связи попытка развития одной части целого без построения системы национальной продовольственной конкурентоспособности не может дать ожидаемого результата.

2. Практика показывает, что на усиление интеграционной мотивации компаний для участия в межгосударственных объединениях в современных условиях начинают воздействовать недостаточная конкурентность внутреннего рынка и качество экономического роста той или иной страны-участника. В таких условиях интеграционное поле продовольственной конкурентоспособности начинает менять свои очертания и масштабы, что неизбежно вызывает потребность модификации экономического взаимодействия входящих в него стран.

3. В аспекте усиления национальной продовольственной конкурентоспособности значимым приоритетом является использование преимуществ региональной экономической интеграции в рамках торгово-экономических сообществ в формате Союзного государства, Евразийского экономического союза в контексте унификации национальных законодательств, с внесением соответствующих изменений в договорно-правовую базу и институциональную структуру. Для этого необходимо установление единых принципов и правил формирования и функционирования крупных интеграционных структур в агропродовольственной сфере, а также гармонизация ответственности за нарушение таких требований. 
4. Рассматривая проблемы формирования интеграционного поля продовольственной конкурентоспособности международных интеграционных объединений и тесно связанной с ней продовольственной независимости стран-участников, можно констатировать, что это комплексное явление международной экономики, проявляющееся в трех основных формах. Во-первых, как объективная мировая тенденция, развивающаяся в результате интернационализации хозяйственной жизни и упрочения разнообразных международных связей между государствами, представляющими их субъектами хозяйствования и отраслевыми комплексами. Во-вторых, как концепция, предполагающая решение различных проблем, принимающих все более глобальный характер, особенно в таких областях, как экология, финансы, транспорт, миграция населения и др. В-третьих, как международный проект одних субъектов мирового рынка (корпораций, стран), направленный на повышение их конкурентоспособности за счет других субъектов.

\section{С- Сияск использованных источников}

1. Гусаков, В. Г. Методические рекомендации по созданию продуктовых компаний / В. Г. Гусаков, М. И. Запольский. - Минск : Ин-т систем. исслед. в АПК НАН Беларуси, 2014. - 155 с.

2. Запольский, М. И. Научные основы интеграционных процессов в АПК Беларуси / М. И. Запольский //
Изв. НАН Беларуси. Сер. аграр. наук. - 2015. - № 2. C. 30-35.

3. Механизмы конкурентоспособного развития АПК Беларуси в условиях функционирования ЕЭП и ЕврАзЭС / В. Г. Гусаков [и др.]. - Минск : Беларус. навука, 2014. - 277 с.

4. Микоян, Ю. Р. Характеристика и роль транснациональных корпораций в России и в мировой экономической системе / Ю. Р. Микоян, Э. Г. Абдулла-Заде // Экономика с.-х. и перераб. предприятий. - 2014. - № 3.C. $40-43$.

5. Мясникович, М. В. Интеграция в ЕЭП, ЕврАзЭС и СНГ: вектор перспективы / М. В. Мясникович // Белорус. экон. журн. - 2013. - № 2. - С. 4-17.

6. Научные основы сбалансированной агропромышленной стратегии Беларуси в Евразийском экономическом союзе / В. Г. Гусаков [и др.]. - Минск : Беларус. навука, 2015. - 259 с.

7. Формирование эффективных форм взаимодействия агропромышленных организаций в рамках ЕАЭС / М. И. Запольский [и др.] // Перспективные направления современного развития АПК: вопросы теории и методологии / В. Г. Гусаков [и др.] ; редкол.: В. Г. Гусаков (гл. ред.) [и др.] ; под ред. В. Г. Гусакова. - Минск : Ин-т систем. исслед. в АПК НАН Беларуси, 2020. - С. 98-101.

8. Фролова, Т. А. Интегративная роль инвестиционных стратегий ТНК / Т. А. Фролова, Л. И. Лукьяненко // Белорус. экон. журн. - 2013. - № 4. - С. 81-96.

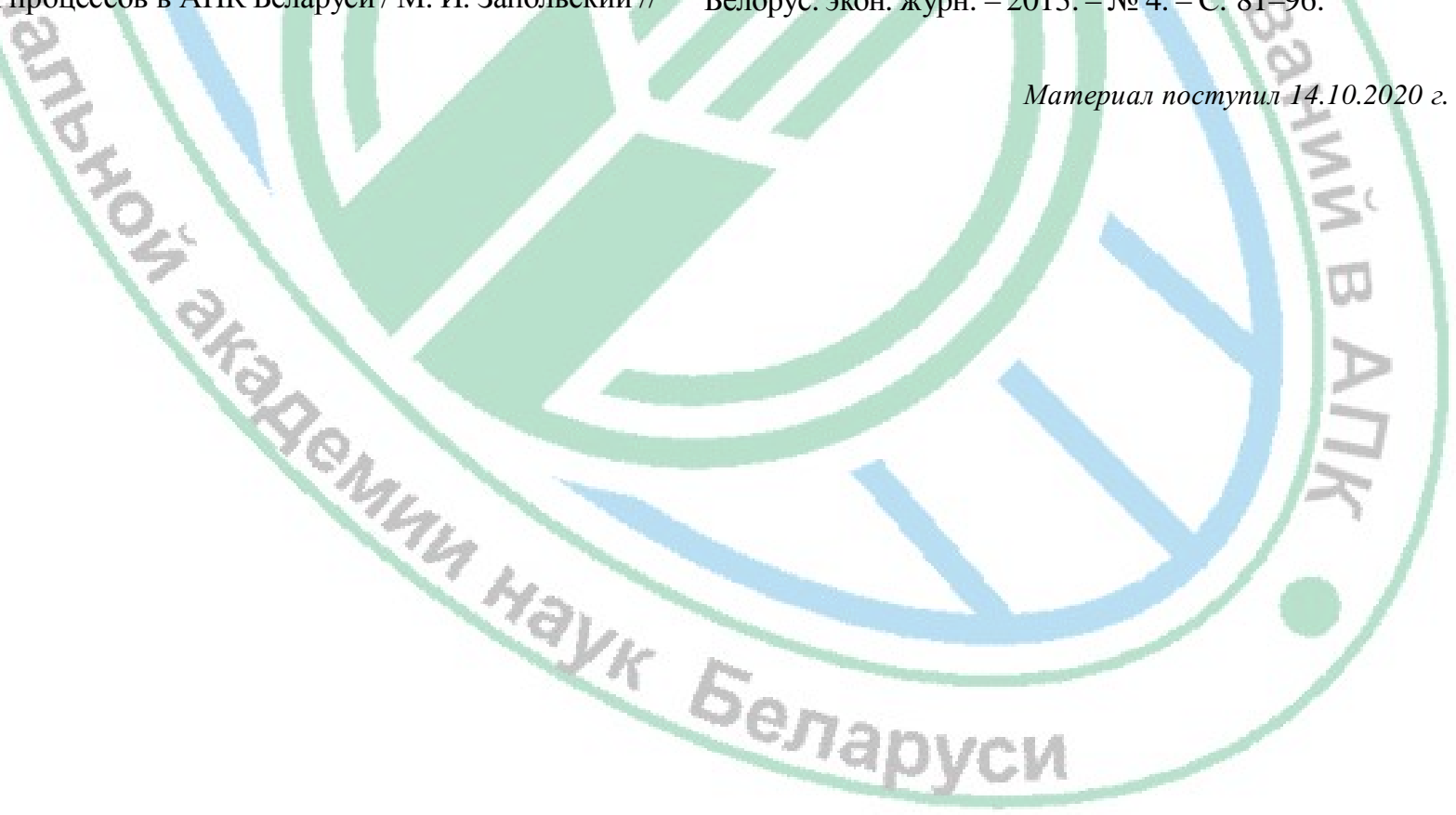

